\title{
MAPEAMENTO DE ÁREAS COM VEGETAÇÃO DE MÉDIA E ALTA DENSIDADE NO MUNICÍPIO DE PALMERINA - PE UTILIZANDO TÉCNICAS DE AEROFOTOGRAMETRIA DE PEQUENO FORMATO OBTIDAS POR VANTS
}

\author{
Renilson Pinto da Silva Ramos ${ }^{(a)}$, Rodolfo Alexandre da Silva Gomes de Deus ${ }^{(b)}$, \\ Fernando da Silva Alexandre $^{(\mathrm{c})}$, Daniel Dantas Moreira Gomes ${ }^{(\mathrm{d})}$ \\ (a)Universidade de Pernambuco - UPE renilsonr5@ hotmail.com, \\ (b)Universidade de Pernambuco - UPE rdolfodeus@gmail.com, \\ (c)Universidade de Pernambuco - UPE fnando257@ hotmail.com, \\ (d) Universidade de Pernambuco - UPE daniel.gomes@upe.br
}

Eixo: GEOTECNOLOGIAS E MODELAGEM ESPACIAL EM GEOGRAFIA FÍSICA

\begin{abstract}
Resumo/
Este artigo tem como objetivo a delimitação e análise da vegetação do centro urbano da cidade de Palmerina. No primeiro momento foi feito um estudo e análise de um material bibliográfico sobre o trabalho. Para fazer o estudo utilizou-se vinte e um pontos de controle e um mosaico foi feito com setecentos e oitenta e quatro cenas dos onze vôos feitos em 03/10/2016 até 20/10/2016 realizados em quase cem metros, com um veículo aéreo não tripulado, Ou VANT, o Phantom 3 advanced, este VANT tem uma câmera RGB de $12 \mathrm{M}$, está equipado com um GPS e um GLONASS. As cenas foram processadas no software da Agisoft Company, Agisoft Photoscan Professional, onde foi gerado o mosaico com as cenas dos vôos. O mosaico foi exportado e utilizado no software da Empresa ESRI, ArcGIS 10.4.1, para fazer a delimitação da vegetação e os cálculos sobre a área do estudo.
\end{abstract}

Palavras-chave: sensoriamento remoto, cartografia, VANT.

\section{Introdução}

As possibilidades de um mapa ser arte ou ciência, entretanto também pode vir a não ser nenhum dos dois, apenas uma técnica que através do uso de símbolos pode ser usada na compreensão de diversas áreas (DUARTE, 2008). É dito que a Cartografia é uma arte pelo necessidade de fins estéticos na confecção de seus produtos e uma ciência pois ela é possuidora de toda uma metodologia para a construção de suas cartas, mapas e plantas, entretanto sendo ciência ou arte, é fato que a Cartografia é de extrema importância para a organização de uma determinada localidade, pois com a finalidade de gerir o espaço em que está inserido, o ser humano sempre tentou melhor organizar-se para planejar o seu ordenamento territorial, uma das formas de melhor realizar esses planejamento é obter dados para uma formulação de planos mais eficazes, e uma das formas de melhor visualizar esses dados é através da Cartografia.

Uma das formas modernas de gerar dados e confeccionar os produtos da Cartografia é utilizando das geotecnologias. Integrando o que se encaixa dentro da esfera das geotecnologias, está o Sensoriamento 
OS DESAFIOS DA GEOGRAFIA FÍSICA NA FRONTEIRA DO CONHECIMENTO

Instituto de Geociências - Unicamp

Campinas - SP

28 de Junho à 02 de Julho de 2017

Remoto, que Rosa (2009) defini por uma maneira de obter informações sobre um ambiente sem ter contato com ele, por intermédio de sensores, que captam a energia eletromagnética emitida pelo sol e refratada pela superfície terrestre, sendo esses definidos como sensores passivos, e também por intermédio de sensores ativos, como o radar, que emite ondas e as recebe, obtendo assim informações sobre o meio.

Os primeiros indícios sobre Sensoriamento Remoto, depois da teoria acerca da luz estar mais formulada e já haver algumas câmeras desenvolvidas, no século XIX, como a fixação de câmeras fotográficas em pombos e balões, e é só em 1909 que se consegue a primeira fotografia tirada de uma aeronave, e é nas décadas de 1940-1950 que começam a ser fixadas câmeras em aeronaves, mas um satélite de análise das condições da superfície terrestre veio a ser lançado pela Rússia, em 1957, para fins militares, o SPUTNIK (BATISTELLA, 2008). Embora do fato de que ele vem sendo utilizado desde 1859, só foi por volta dos anos de 1970 que o termo Sensoriamento Remoto foi incorporado dentro da linguagem científica (ROSA, 2009).

Em qualquer objeto que venha a ter interação com a energia eletromagnética ocorrem três tipos de fenômenos, a transmissão, a absorção e a reflexão. A faixa do espectro eletromagnético que será refletida, absorvida e transmitida dependerá das características físico-químicas do objeto em que a energia está incidindo. No processo de interação da radiação eletromagnética a vegetação realiza a fotossíntese por parte de seus pigmentos como a clorofila, xantofilas e carotenos. A absorção por parte da vegetação limita-se a faixa do espectro eletromagnético que corresponde a $04 \mu \mathrm{m}-0,72 \mu \mathrm{m}$, correspondendo na maior parte do tempo na região do visível que corresponde a $0,53 \mu \mathrm{m}-0,59 \mu \mathrm{m}$ que pode ser identificada na cor verde (PONZONI, 2012).

Com dados advindos do Sensoriamento Remoto é possível realizar as aplicações mais distintas para o estudo da vegetação, sendo possível a obtenção de dados para a confecção dos mais diversos tipos de mapas para a realização dos mais diversos estudos, abrindo possibilidade também para a realização de monitoramentos, ou mapeamentos que visem o ordenamento territorial que envolve áreas com vegetação, auxiliando a formulação de planejamentos que visem a gestão de áreas que podem ser protegidas, definidas Lei $\mathrm{n}^{\mathrm{0}}$ 12.651, de 25 de maio de 2012 que definem áreas de preservação permanente ou APPs, como espaços territoriais legalmente, ambientalmente frágeis ou vulneráveis, e que podem ser em locais públicos ou privados, rurais ou urbanos, com vegetação nativa ou não. Dentro do código florestal quando se vem a falar de APPs dentro de perímetro urbano também é importante salientar a funções que elas são possuidoras, como servindo para proteção dos solos prevenindo que venha a ocorrer desastres associadas com ocupações de encostas, preservação de corpos d'água, manutenção da permeabilidade do solo, evitando enxurradas e enchentes, atenuação de desequilíbrios climáticos e como refúgio para a fauna. 


\section{OS DESAFIOS DA GEOGRAFIA FÍSICA NA FRONTEIRA DO CONHECIMENTO Instituto de Geociências - Unicamp \\ Campinas - SP \\ 28 de Junho à 02 de Julho de 2017}

O mapeamento ou monitoramento dessas áreas pode ser realizado com a utilização de VANTs

(Veículos aéreos não tripulados), que por conta da velocidade na obtenção de novos dados tem ganho espaço dentro do meio técnico-científico, podendo proporcionar análises multitemporais com imagens de alta resolução com a autonomia do usuário quanto a seu planejamento, sendo muito mais fácil e acessível que outros meios de obtenção desses dados (BRAZ, 2015).

Há uma crescente utilização de dados auferidos por intermédio da aerofotogrametria para a realização dos mais diversos estudos, a utilização de VAN's (Veículos aéreos não tripulados) tem crescido nessa área, pois em relação ao custo, comparando com outros métodos de aquisição de imagens de alta resolução provindas de sensores passivos tanto orbitais, quanto suborbitais aparecem como alternativa muito mais viável, além da autonomia nos voos por parte do piloto e uma melhor organização periódica nas datas referentes as tentativas de aquisição dos dados, tornando a utilização de VANT's uma forma muito viável para estudos que tenham em seu escopo o Sensoriamento Remoto (MITISHITA, 2014).

\section{Localização do objeto de estudo}

Palmerina é um município brasileiro localizado na unidade federativa de Pernambuco, entre a latitude $09^{\circ} 00^{\prime} 16^{\prime \prime}$ sul e a uma longitude $36^{\circ} 19^{\prime} 33^{\prime \prime}$ oeste, e ficando a $241 \mathrm{Km}$ de distância da capital Recife.

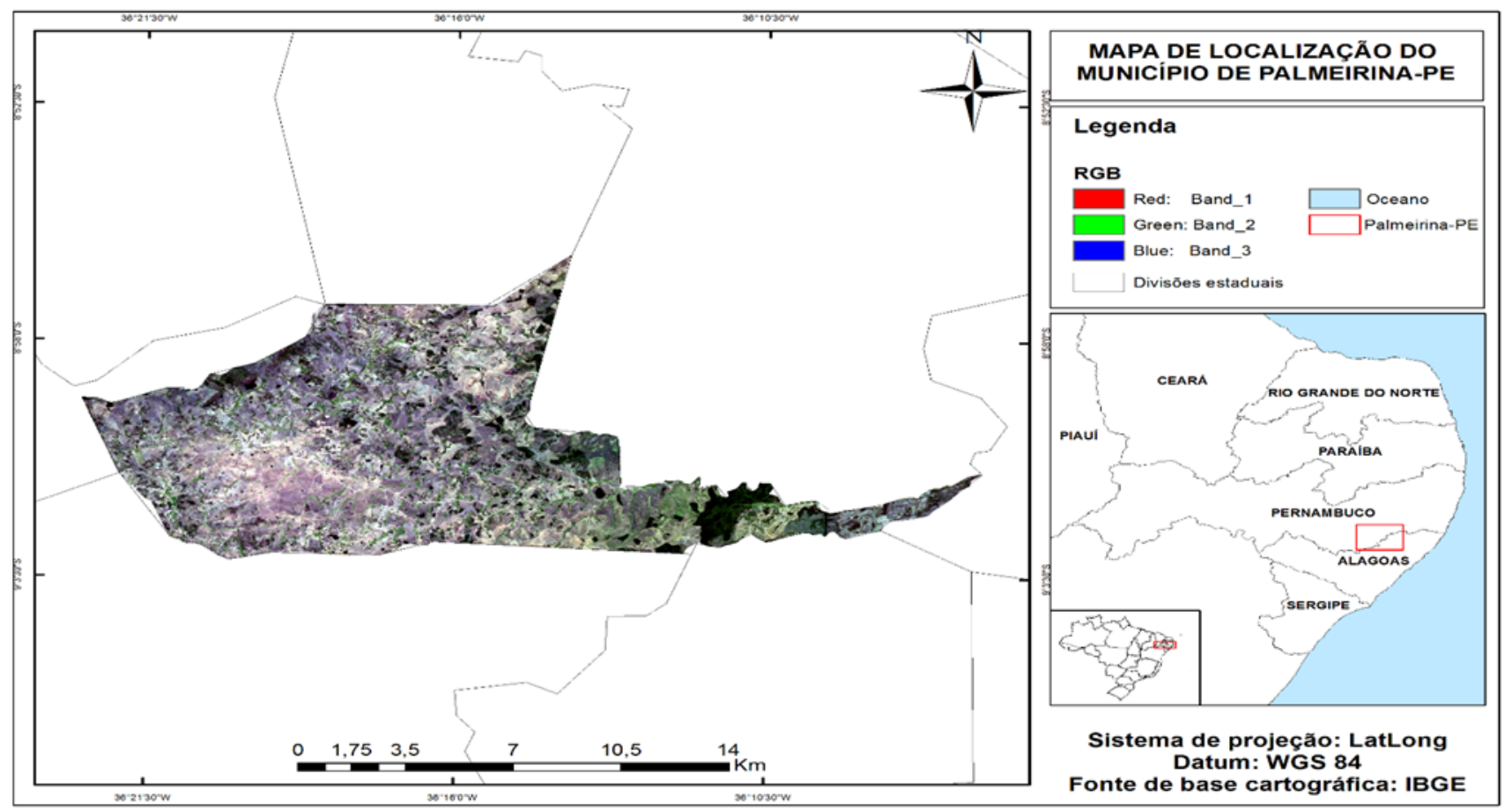

Figura 1 - Mapa de localização do município de Palmerina-PE 


\section{OS DESAFIOS DA GEOGRAFIA FÍSICA NA FRONTEIRA DO CONHECIMENTO \\ Instituto de Geociências - Unicamp \\ Campinas - SP \\ 28 de Junho à 02 de Julho de 2017}

\section{Metodologia de trabalho}

\section{Materiais}

Foi realizado em primeiro lugar a definição do estudo e o local que seria elaborado, todo um levantamento bibliográfico foi realizado e manuais técnicos, livros e artigos forma consultados para melhor fornecer um embasamento teórica para conferir a melhor caracterização científica para o trabalho.

Para um melhor trabalho no processamento digital das imagens, foram coletados 21 pontos de controle distribuídos em toda área urbana do município de Palmerina, para isso foi utilizado o GPS Garmin etrex venture hc.

O Phantom 3 Advanced foi o VANT utilizado no trabalho, esse VANT é equipado com um GPS e um GLONNAS, pesa $1280 \mathrm{~g}$, é possuidor de uma velocidade de subida de $5 \mathrm{~m} / \mathrm{s}$ e de descida de $3 \mathrm{~m} / \mathrm{s}$, chega até uma velocidade de $57 \mathrm{Km} / \mathrm{h}$, é equipada com um sensor passivo que é uma câmera RGB de $12.76 \mathrm{M}$ com lentes FOV $94^{\circ} 20 \mathrm{~mm}$.

\section{Planejamento de voo}

Foi realizado um planejamento prévio levando em conta as condições meteorológicas da área para conferir um melhor voo para o VANT, levando em consideração uma sobreposição de longitudinal de $85 \%$ e lateral de $45 \%$, com voos com altura aproximada de 100 metros em média, e com horários próximos às 12:00 horas para evitar efeito de sombreamento e consequentemente perda de dados.

\section{Execução de voos}

Foram realizados o número total de onze voos, com uma duração de tempo que variou de 15 minutos até 23 minutos, elevando até 50 metros no manual, sendo após isso acionado o piloto automático que irá cumprir os voos cobrindo as áreas que foram determinadas no planejamento, foram coletadas ao todo 784 cenas com resolução $2,5 \mathrm{Cm}$, durante um período que durou de 03/06/2016 até 20/06/2016, os dados referentes aos voos podem ser melhor conferidos na tabela 1.

Tabela I - Descrição dos planos de voo.

\begin{tabular}{c|c|c|c|c|}
\hline Número de voo & Data & Horário de decolagem & Cenas & Altura média $(\mathrm{m})$ \\
\hline Flight 01 & $\mathbf{0 3 / 0 6 / 2 0 1 6}$ & $\mathbf{1 0 : 4 5}$ & 49 & $\mathbf{9 5 , 1 0}$ \\
\hline Flight 02 & $\mathbf{0 3 / 0 6 / 2 0 1 6}$ & $11: 20$ & 45 & $\mathbf{9 6 , 8 5}$ \\
\hline Flight 03 & $\mathbf{0 3 / 0 6 / 2 0 1 6}$ & $13: 50$ & 57 & $\mathbf{9 7 , 5 9}$ \\
\hline Flight 04 & $\mathbf{0 4 / 0 6 / 2 0 1 6}$ & $11: 05$ & 82 & $\mathbf{9 8 , 2 7}$ \\
\hline
\end{tabular}




\begin{tabular}{|c|c|c|c|c|}
\hline $\begin{array}{l}\text { XVII Simpós } \\
\text { de Geografia } \\
\text { I Congress } \\
\text { de Geogr }\end{array}$ & $\begin{array}{ll}\text { sileiro } & \text { OS DE } \\
\text { clicanala } \\
\text { física }\end{array}$ & $\begin{array}{r}\text { GEOGR } \\
\text { Instit } \\
28\end{array}$ & $\begin{array}{l}\text { RONT } \\
\text { - Uni } \\
\text { lo de } 2\end{array}$ & ECIMENTO \\
\hline Flight 05 & $04 / 06 / 2016$ & $12: 56$ & 71 & 98,51 \\
\hline Flight 06 & $08 / 06 / 2016$ & $10: 14$ & 77 & 98,63 \\
\hline Flight 07 & $12 / 06 / 2016$ & $13: 23$ & 97 & 98,55 \\
\hline Flight 08 & $13 / 06 / 2016$ & $11: 58$ & 101 & 99,40 \\
\hline Flight 09 & 17/06/2016 & $12: 34$ & 29 & 99,05 \\
\hline Flight 10 & 18/06/2016 & $11: 23$ & 105 & 97,38 \\
\hline Flight 11 & $20 / 06 / 2016$ & $12: 47$ & 71 & 99,91 \\
\hline
\end{tabular}

\section{Processamento digital de imagens}

As imagens obtidas com o VANT foram processadas no software Agisoft PhotoScan Professional da empresa Agisoft, para a confecção do mosaico que posteriormente foi exportado para a utilização e análises no software da empresa ESRI, ArcGIS 10.4.1, onde foi reprojetado para o sistema de projeção cartográfica UTM, DATUM WGS, Zona $24 \mathrm{~S}$, para melhor trabalhar-se com o mosaico.

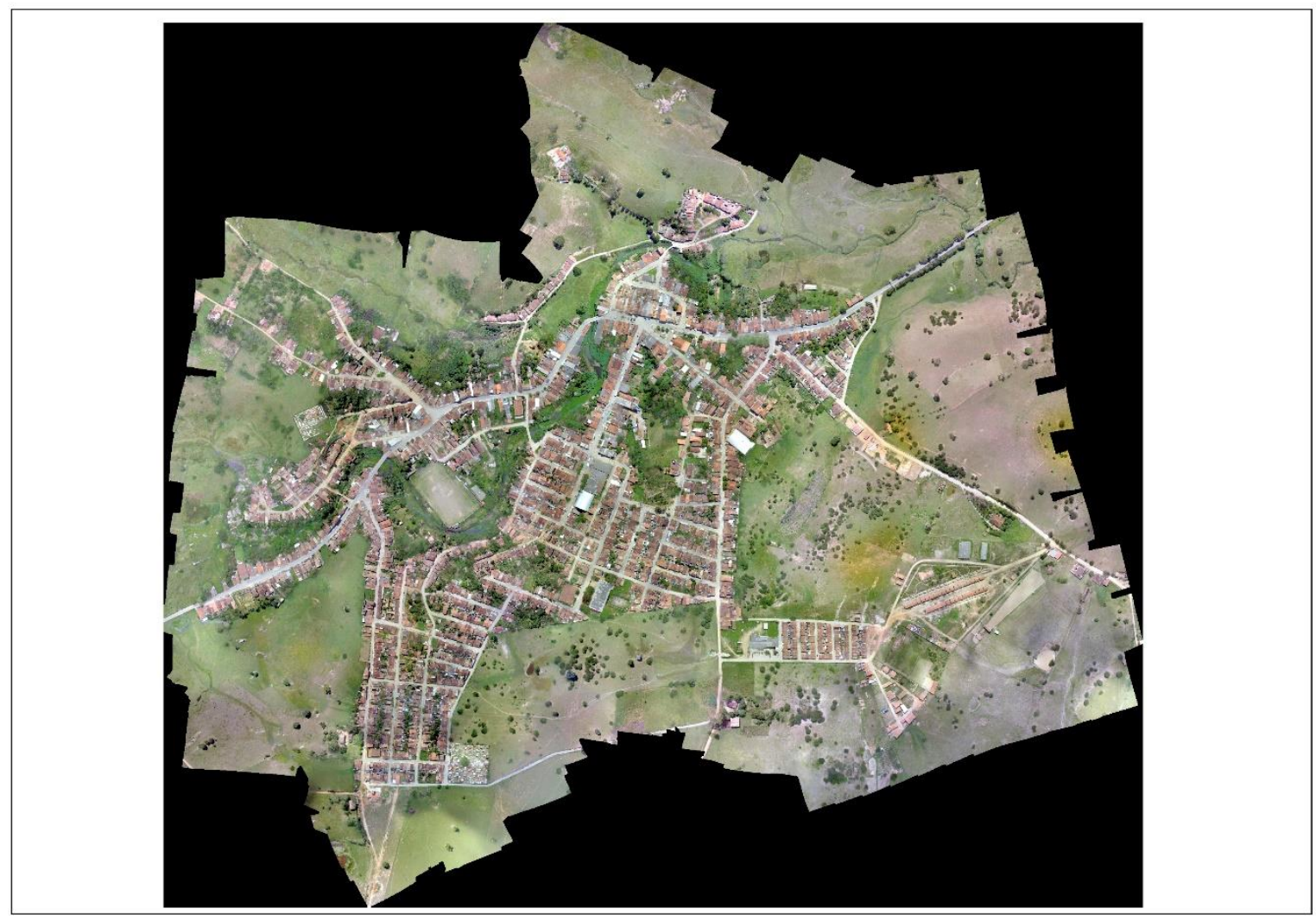

Figura 3 - Mosaico em cor normal. 
Foi criado um arquivo no formato shapefile para o desenho das áreas urbanas, hidrografia e para o contorno da vegetação de médio e pequeno porte, numa escala e 1:1000, com os produtos gerados foi possível a realização de cálculos referentes a quantidade em metros quadrados que a vegetação de médio e grande porte cobre no centro urbano do município, e por último foi realizado a confecção de um mapa.

\section{Resultados e Discussão}

Com a utilização do mosaico gerado após a realização do processamento das imagens obtidas em onze voos realizados pelo VANT, foi realizada a análises e confecção do mapa do centro urbano do município de Palmerina-PE.

Foi possível através das análises da área estudada, identificar e realização a delimitação de áreas possuidoras de médio e grande porte, realizada numa escala utilizada para plantas urbanas que visam servir de base para dados cadastrais, 1:1000, foram circuladas as áreas que apresentarão características arbustivas e arbóreas dentro do centro urbano do município em questão e em seus arredores, e calculada em qual quantidade essa vegetação vem a aparecer.

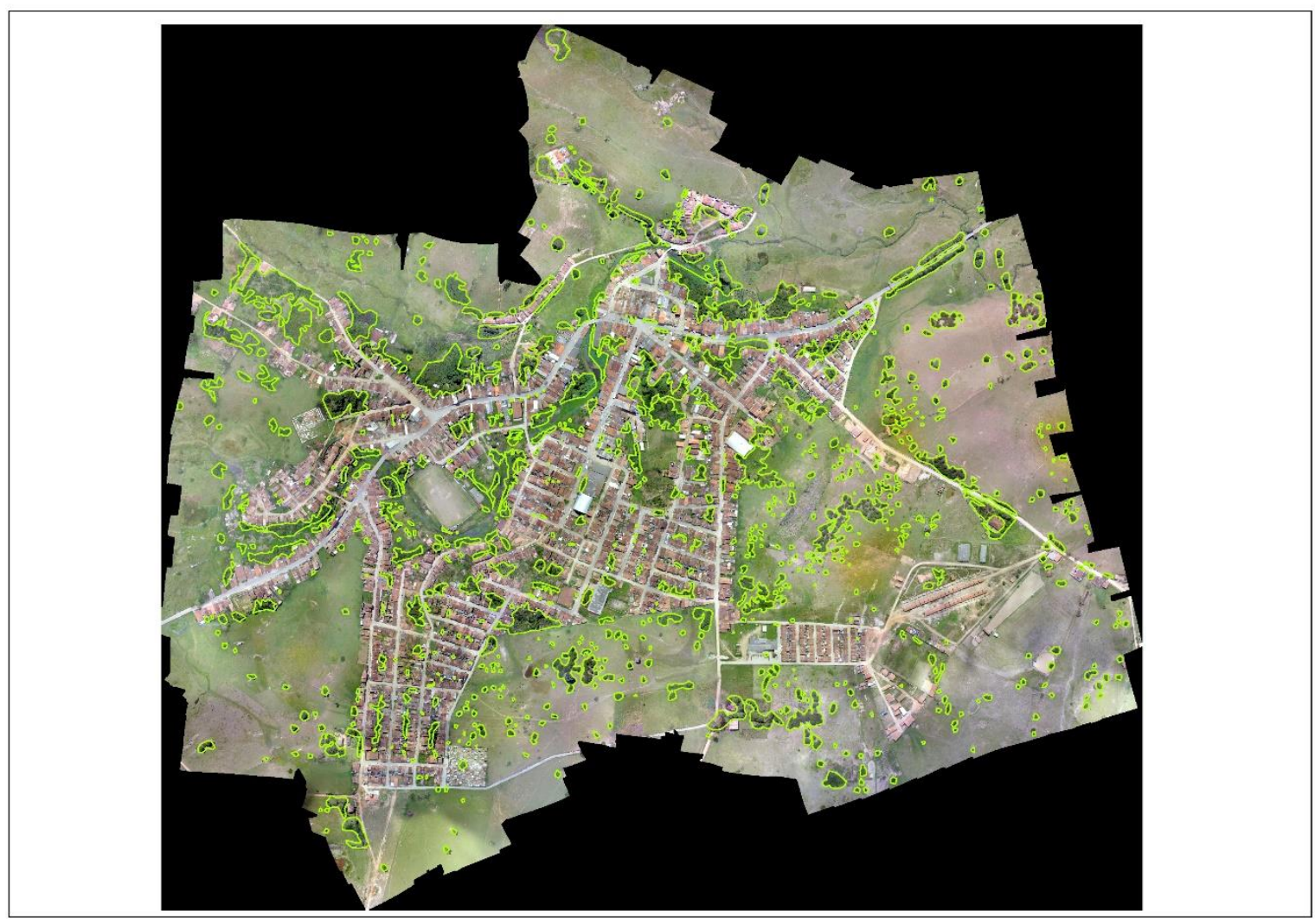

Figura 4 - Mosaico em cor normal com a delimitação da vegetação. 


\section{OS DESAFIOS DA GEOGRAFIA FÍSICA NA FRONTEIRA DO CONHECIMENTO Instituto de Geociências - Unicamp \\ Campinas - SP \\ 28 de Junho à 02 de Julho de 2017}

A vegetação de pequeno e grande porte cobre na área estudada o equivalente a $173802,284 \mathrm{M}^{2}$, aparecendo em sua maior quantidade na forma de mata ciliar do sistema hídrico do município, em outras áreas aparece próximos a residências e nas proximidades de áreas destinadas a atividades agrícolas.

Mostrando-se como um município com relativa quantia de arborização, é possível observar uma preocupação com a questão da arborização que acaba por ser importantes em centros urbanos como aproximação de condições ambientais que podem ser ditas como normais (GOMES, 2003).

A vegetação também acaba por realizar equilíbrio climática dentro de áreas urbanas, favorecendo a atenuação de temperaturas fortemente influenciadas por ambientes totalmente antropizados com a construção de edificações (BARBOSA, 2005).

Tendo isso em vista, juntamente com os resultados obtidos nas análises é possível observar que o município de Palmerina sendo dotado dessa boa quantia de arborização, é possuidora de bons meios para o equilíbrio climático a aproximações com as condições ambientais, favorecendo uma melhor condição de vida para a população do centro urbano do município.

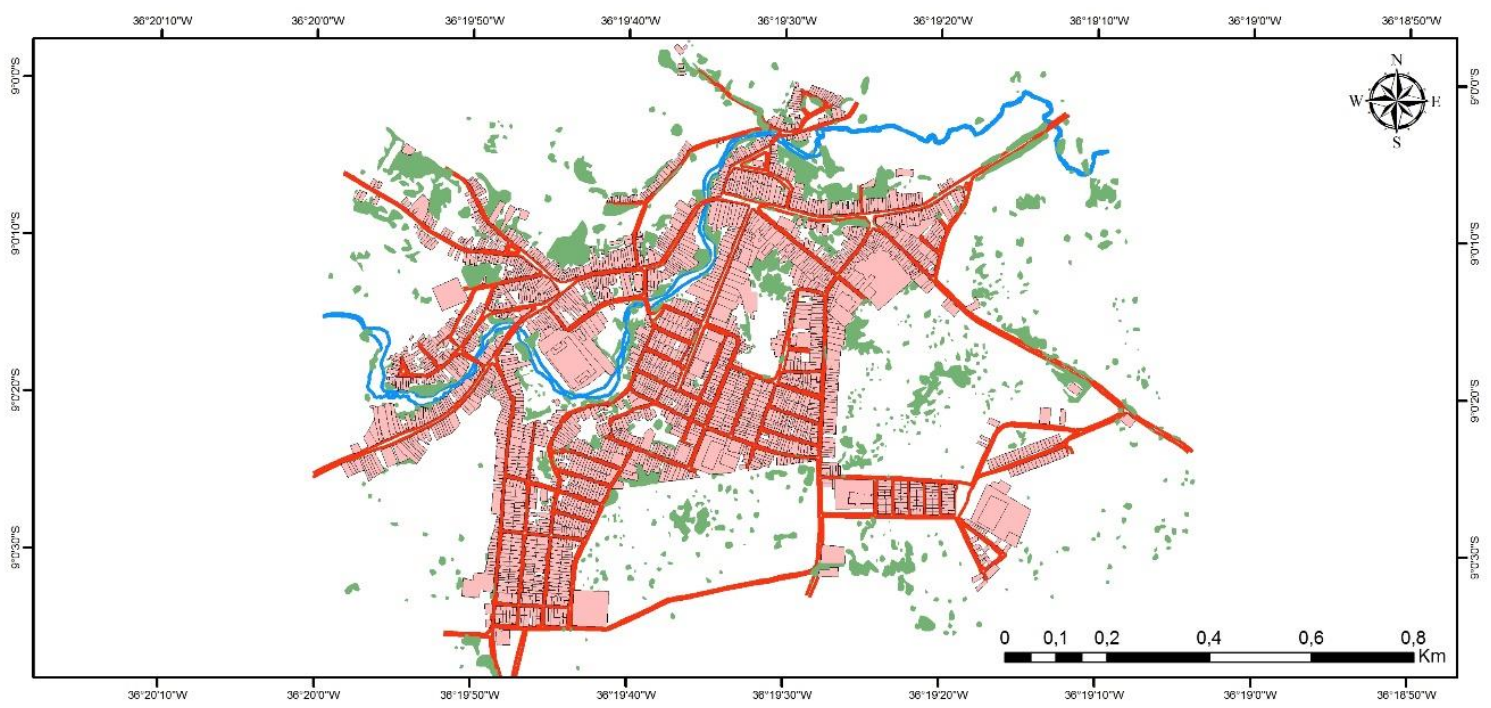

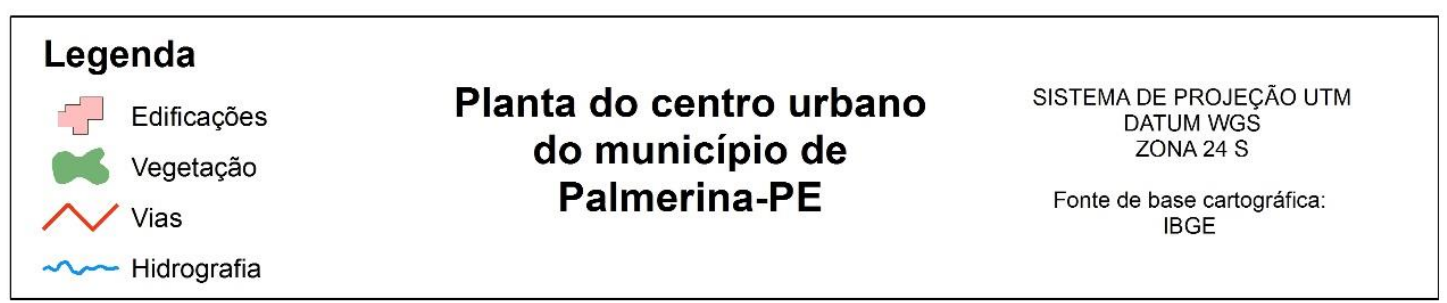

Figura 5 - Planta do centro urbano do município de Palmerina-PE. 


\section{Conclusões}

Foi possível por intermédio das imagens de alta resolução do VANT, identificar a vegetação de médio e grande porte do município de Palmerina-PE de maneira muito eficaz, o que auxiliou na confecção de uma planta com a escala de 1:1000 com os detalhes suficientes para distinção de vários elementos presentes na imagem, mostrando a eficácia e a possibilidade do uso de VANTs na identificação desse tipo de vegetação para a delimitação de áreas que se apresentam como APPSs.

Com o uso de VANTs na identificação de APPs é possível auferir dados de alta resolução dentro do período que for decidido pelo o usuário e com o custo muito mais acessível que outros meios, em comparação principalmente com os dados de alta resolução vindo de sensores passivos orbitais, facilitando assim o acesso a órgãos públicos, visando melhores planejamentos e monitoramentos de áreas categorizadas como APPs.

\section{Agradecimentos}

Os autores agradecem ao Conselho Nacional de Desenvolvimento Científico e Tecnológico (CNPq) pelo financiamento dos recursos do projeto de pesquisa "Diagnóstico geoambiental das bacias hidrográficas do Estado de Pernambuco: geoprocessamento aplicado ao manejo e conservação dos recursos naturais", junto ao Programa Institucional de Bolsas de Iniciação Científica (PIBIC) da Universidade de Pernambuco (UPE), e ao Laboratório de Geoprocessamento e Modelagem Ambiental pela cessão dos dados cartográficos vetorizados e imagens de satélites.

\section{Referência bibliográficas}

BARBOSA, Ricardo Victor Rodrigues. Áreas verdes e qualidade térmica e ambientes urbanos: Estudo em microclimas em Maceió (AL). 2005. Dissertação (Mestrado) - Escola de Engenharia de São Carlos Universidade de São Paulo, 2005.

BATISTELlA, Matheus, CRISCUOLO, Cristina. BOLFE, Édson Luis. Satélites de recursos naturais como suporte à gestão ambiental. Geoinformação e Monitoramento Ambiental na América Latina. Senac Editora. 2008. p. 21- 52.

BRASIL, LEI N ${ }^{\circ}$ 12.651, DE 25 DE MAIO DE 2012. Dispõe sobre a proteção da vegetação nativa; altera as Leis $\mathrm{n}^{\text {os }} 6.938$, de 31 de agosto de 1981, 9.393, de 19 de dezembro de 1996, e 11.428, de 22 de dezembro de 2006; revoga as Leis $\mathrm{n}^{\text {os }} 4.771$, de 15 de setembro de 1965, e 7.754, de 14 de abril de 1989, e a Medida Provisória $\mathrm{n}^{\mathrm{0}}$ 2.166-67, de 24 de agosto de 2001; e dá outras providências. Disponível em: <http://www.planalto.gov.br/ccivil_03/_Ato2011-2014/2012/Lei/L12651.htm>. Acesso em 29/10/2016.

BRAZ, Adalto Moreira. BORGES, Josué Pedro dos Santos. BERNARDES, Deany Cristina da Silva. TEREZAN, Luiz Henrique. Análise da aplicação de VANT na atualização de cadastro florestal com uso de 
pontos de controle. Anais XVII Simpósio Brasileiro de Sensoriamento Remoto - SBSR, João Pessoa-PB, Brasil, 25 a 29 de abril de 2015, INPE

DUARTE, Paulo Araújo. Fundamentos de Cartografia. 3. Ed. Editorada da UFSC, 2008.

GOMES, Marcos Antônio Silvestre, SOARES, Beatriz Ribeiro. A vegetação nos centros urbanos: Considerações sobre os espaços verdes em cidades médias brasileiras. Estudos Geográficos, Rio Claro, 1(1): 19-29, Junho, 2003.

Ministério do Meio Ambiente, Áreas de Preservação Permanente Urbanas. Disponível em: <http://www.mma.gov.br/cidades-sustentaveis/areas-verdes-urbanas/áreas-de-proteção-permanente>. Acesso em: $27 / 10 / 2016$

MITISHITA, E. A.; GONCALVES, J. E. ; GRACA, N. L. S. S. ; CENTENO, Jorge Antonio Silva ; MACHADO, Álvaro Muriel Lima. O uso. In: XXVI Congresso Brasileiro de Cartografia, 2014, Gramado. Anais do XXVI Congresso Brasileiro de Cartografia, 2014.

PONZONI, Flávio Jorge. Sensoriamento remoto da vegetação. Oficina de textos, 2012. ROSA, Roberto. Introdução ao Sensoriamento Remoto. EDUFU, 2009. 